\title{
Surgical and Anesthetic Management of Postpartum Hemorrhage Forty-Five Days After Cesarean Section*
}

\author{
Sezaryenden Kırkbeş Gün Sonra Postpartum Kanamanın Cerrahi ve \\ Anestezi Yönetimi
}

\author{
M. Funda Cevher Akdulum¹, Nuray Camgoz Eryilmaz², Dudu Berrin Gunaydin², Ayse Borkluce², \\ Esra Isci Bostanci ${ }^{1}$, Ahmet Erdem ${ }^{1}$ \\ ${ }^{1}$ Gazi University School of Medicine, Department of Obstetrics and Gynecology, Ankara, Turkey \\ ${ }^{2}$ Gazi University School of Medicine, Department of Anesthesiology and Reanimation, Ankara, Turkey \\ *It has been presented as a free paper at the Balkan States Anesthesia Days VII, between April 30 to May 2, 2021.
}

Dear editor,

A cumulative blood loss $\geq 1,000 \mathrm{~mL}$ accompanied by hypovolemia within 24 hours after delivery regardless of the delivery route is defined as postpartum hemorrhage (PPH) which is called as primary PPH. However, secondary PPH occurs 24 hours after delivery up to 12 weeks postpartum which is more common during normal vaginal delivery but rarely seen after cesarean section (CS) (1). The PPH has been still the most common cause of maternal mortality and morbidity which has a rate of 13.1 in 100.000 live births in 2019 (2). The aim of this report is to address multidisciplinary approach to secondary (delayed) PPH in a patient 45 days after CS according to adapted massive transfusion protocol (MTP).

A 29-year-old parturient with abnormal bleeding was admitted 45 days after CS. Coagulation profile and fibrinogen before PPH diagnosis was not remarkable. The ultrasound was free of any retained placental products/subinvolution. The hemoglobin $(\mathrm{Hb})$ decreased from 10.3 to $6.9 \mathrm{~g} \mathrm{dL}^{-1}$. After IV infusion of 20 IU of oxytocin/1000 mL Ringer's lactate, 0.2 $\mathrm{mg}$ of im methylergonovine, $100 \mu \mathrm{g}$ in $10 \mathrm{~mL}$ carbetocin and $600 \mu \mathrm{g}$ of transrectal misoprostol were administered. Meanwhile, IV tranexamic acid (TXA) (1 g) and fibrinogen concentrate ( $2 \mathrm{~g}$ ) were given. Fibrinogen levels were $585 \mathrm{mg} \mathrm{dL}^{-1}$ (on admission), $247.8 \mathrm{mg} \mathrm{dL}^{-1}$ (after $1 \mathrm{~g}$ of TXA and $2 \mathrm{~g}$ of fibrinogen administration) and $198.7 \mathrm{mg} \mathrm{dL}^{-1}$ (before another $1 \mathrm{~g}$ of fibrinogen administration). After obtaining written informed consent, patient underwent emergency exploratory surgery. General anesthesia was performed with propofol rocuronium followed by $1 \mathrm{MAC}$ sevoflurane in $50 \% \mathrm{O}_{2}$ /air mixture plus remifentanil infusion using standard monitorization. Lateral hemostatic suturation and bilateral uterine and hypogastric artery ligations were performed. Following $6 \mathrm{U}$ of red blood cells (RBC), $6 \mathrm{U}$ of fresh frozen plasma (FFP) and $10 \mathrm{~mL}$ calcium $10 \%$ administration, $\mathrm{Hb}$ was $7.7 \mathrm{~g} \mathrm{dL}^{-1}$ and platelet count was $237.000 \mathrm{\mu g}^{-1}$. One gram of fibrinogen concentrate was given to target FIBTEM A5 $16 \mathrm{~mm}$ in ROTEM and $>2 \mathrm{~g} \mathrm{~L}^{-1}$ (afterwards it reached to $303 \mathrm{mg} \mathrm{dL}^{-1}$ ).

Delayed PPH after CS was managed by pharmacological (uterotonics, antifibrinolytic and procoagulants) and surgical (sutures and ligations of bleeding arteries) interventions. After TXA, use of fibrinogen along with RBC:FFP (1:1 ratio driven protocol) was guided with standard laboratory tests and ROTEM consecutively to increase $\mathrm{Hb}$ up to $9 \mathrm{~g} \mathrm{dL}^{-1}$.

We previously managed bleeding due to uterine atony/ rupture after vaginal delivery by focusing on role of fibrinogen in the coagulation (3). Physiologically pregnant women have higher fibrinogen level and decreased fibrinolysis than non-pregnant population (4). Hereby, $1 \mathrm{~g}$ TXA and $2 \mathrm{~g}$ fibrinogen concentrates were given in the ward by the obstetricians before emergency surgery. We, anesthesiology team, managed goal directed coagulopathy therapy using ROTEM since fibrinogen level $<2 \mathrm{~g} \mathrm{~L}^{-1}$ and/or FIBTEM A5 $<12 \mathrm{~mm}$ are considered to be predictive of severe hemorrhage as stated in the recent Maternity and Obstetrics Guidelines of the Turkish Ministry of Health (5) (Figure 1).

In conclusion delayed (secondary) PPH was successfully managed by multidisciplinary team approach after early activation of adapted MTP that includes trigger and target values guided by ROTEM and/or standard tests for avoiding unnecessary transfusion that can possibly increase mortality and/ or morbidity.
Received/Geliş tarihi : 04.01.2022 Accepted/Kabul tarihi : 13.01.2022 Publication date 28.01.2022
*Corresponding author: Dudu Berrin Gunaydin • gunaydin@gazi.edu.tr

M. Funda Cevher Akdulum (10) 0000-0003-2285-7112 / Nuray Camgoz Eryilmaz (ㄷ) 0000-0002-8988-7706 Dudu Berrin Gunaydin (1) 0000-0002-0422-5536 / Ayse Borkluce (무 0000-0002-3526-7034 Esra Isci Bostanci (1) 0000-0002-7703-7608 / Ahmet Erdem (ㄴ) 0000-0002-1950-9670

Cite as: Cevher Akdulum MF, Camgoz Eryilmaz N, Gunaydin DB, Borkluce A, Isci Bostanci E, Erdem A. Surgical and anesthetic management of postpartum hemorrhage forty-five days after cesarean section. JARSS 2022;30(1):71-73. 


\section{Major PPH}

Blood loss $\geq 1500 \mathrm{~mL}$ and ongoing bleeding

\section{Order 1st Shock pack}

Consider surgical and non-surgical techniques - transfer of the patient to the OR

Maintain normovolemia by management of hemodynamics and volume status

Monitor noninvasive cardiac output (if available in your unit)

Consider invasive arterial/central monitoring

Replace fluid up to $3.5 \mathrm{~L}$ ( $2 \mathrm{~L}$ isotonic crystalloid $+1.5 \mathrm{~L}$ colloid preferably gelatin) until blood arrives

Transfuse RBC if required clinically hematologically

Transfuse O Rh(-) blood of spesific group-blood type is unknown

Repeat $1 \mathrm{~g}$ IV TXA ( IV infusion within $10 \mathrm{~min}$ )

Consider of cell salvage (if available)

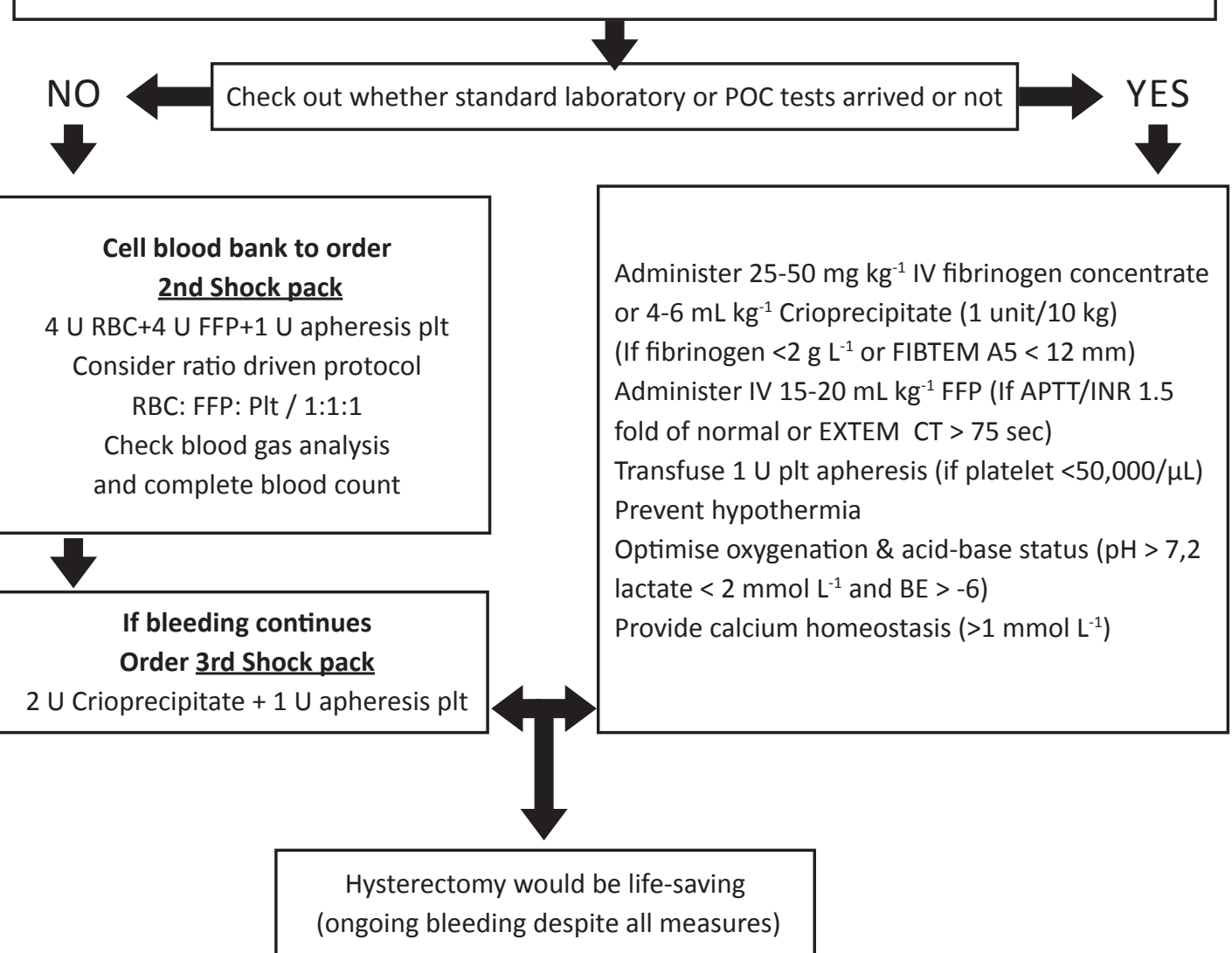

RBC: Red Blood Cell

Plt: Platelet

APTT: Activated partial thromboplastin time

INR: İnternational normalized ratio

POC: Point of Care

Figure 1: Adapted massive transfusion protocol for postpartum hemorrhage of national maternity and obstetrics guidelines. 


\section{AUTHOR CONTRIBUTIONS}

Conception or design of the work: DBG, NCE, MFCA

Data collection: $A B, E I B$

Data analysis and interpretation: DBG, NCE

Drafting the article: DBG, NCE

Critical revision of the article: MFCA, DBG

Other (study supervision, fundings, materials, etc): $A E, E I B$

All authors (MFCA, NCE, DBG, AB, EIB, AE) reviewed the results and approved the final version of the manuscript.

\section{REFERENCES}

1. Practice Bulletin No. 183: Postpartum Hemorrhage. Committee on Practice Bulletins - Obstetrics. Obstet Gynecol 2017; 130(4):e168-e186.

2. https://sbsgm.saglik.gov.tr/Eklenti/40566/0/healthstatistics-yearbook-2019pdf.pdf Health Statistics Yearbook 2019 | Mortality, pg 24

3. Günaydın B, İnan $G$, Turgut $E$, et al. Perioperative management of bleeding due to uterine atony/rupture in a parturient after vaginal delivery and intensive care unit follow-up: Pharmacological, surgical and interventional therapies. Turk J Intensive Care 2020;18:47-53.

4. Thornton P, Douglas J. Coagulation in pregnancy. Best Practice Res Clin Obstet Gynaecol 2010;24(3):339-52.

5. https://hastakanyonetimi.saglik.gov.tr/dokumanlar/rehberler/Modul5-Gebelik_ve_Dogum.pdf 